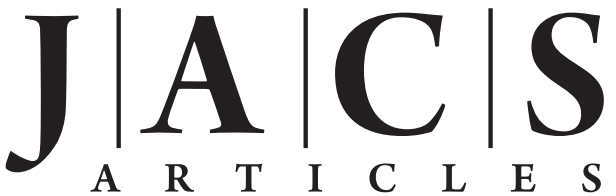

Published on Web 02/16/2010

\title{
Identification of Hydroxyl Protons, Determination of Their Exchange Dynamics, and Characterization of Hydrogen Bonding in a Microcrystallin Protein
}

\author{
Vipin Agarwal, ${ }^{\dagger, \ddagger}$ Rasmus Linser, $^{\dagger}$ Uwe Fink, ${ }^{\dagger}$ Katja Faelber, ${ }^{\dagger, \S}$ and Bernd Reif ${ }^{, \dagger, \|}$ \\ Leibniz-Forschungsinstitut für Molekulare Pharmakologie (FMP), Robert-Rössle-Str. 10, \\ D-13125 Berlin, Germany, and Charité Universitätsmedizin, D-10115 Berlin, Germany
}

Received December 2, 2009; E-mail: reif@fmp-berlin.de

\begin{abstract}
Heteronuclear correlation experiments employing perdeuterated proteins enable the observation of all hydroxyl protons in a microcrystalline protein by MAS solid-state NMR. Dipolar-based sequences allow magnetization transfers that are $>50$ times faster compared to scalar-coupling-based sequences, which significantly facilitates their assignment. Hydroxyl exchange rates were measured using EXSY-type experiments. We find a biexponential decay behavior for those hydroxyl groups that are involved in side chain - side chain $\mathrm{C}-\mathrm{O}-\mathrm{H} \cdots \mathrm{O}=\mathrm{C}$ hydrogen bonds. The quantification of the distances between the hydroxyl proton and the carbon atoms in the hydrogen-bonding donor as well as acceptor group is achieved via a REDOR experiment. In combination with X-ray data and isotropic proton chemical shifts, availability of ${ }^{1} \mathrm{H},{ }^{13} \mathrm{C}$ distance information can aid in the quantitative description of the geometry of these hydrogen bonds. Similarly, correlations between backbone amide proton and carbonyl atoms are observed, which will be useful in the analysis of the registry of $\beta$-strand arrangement in amyloid fibrils.
\end{abstract}

\section{Introduction}

Hydrogen bonds play an important role in stabilizing the fold of a protein. At the same time, they are key for understanding protein function and determine enzymatic activity. ${ }^{1-3}$ Despite their importance, hydrogen bonds are poorly understood, as the proton is only visible in $\mathrm{X}$-ray crystallographic investigations if the achieved resolution exceeds $1.0 \AA .{ }^{4}$ On the other hand, neutron structures of proteins are rarely available. ${ }^{5}$ In solutionstate NMR, hydroxyl protons are difficult to observe, as they are not directly bonded to other spin-1/2 nuclei. Furthermore, they exchange with the solvent quickly and thus easily escape assignment. The elusiveness of hydroxyl protons can be judged by the fact that only a small fraction $(\sim 3 \%)$ of all threonine $\mathrm{H} \gamma 1$ shifts are deposited in the BioMagResBank (BMRB). ${ }^{6}$ Likewise, the $2^{\prime}-\mathrm{OH}$ groups in RNA are accessible only in

\footnotetext{
${ }^{\dagger}$ Leibniz-Forschungsinstitut für Molekulare Pharmakologie.

$\doteqdot$ Present address: Radboud University, Department of Physical Chemistry, Toernooiveld 1, 6525 ED Nijmegen, The Netherlands.

$\$$ Present address: Max-Delbrück-Center für Molekulare Medizin (MDC), Robert-Rössle-Str. 10, D-13125 Berlin, Germany.

"Charité Universitätsmedizin.

(1) Ash, E. L.; Sudmeier, J. L.; Day, R. M.; Vincent, M.; Torchilin, E. V.; Haddad, K. C.; Bradshaw, E. M.; Sanford, D. G.; Bachovchin, W. W. Proc. Natl Acad. Sci. U.S.A. 2000, 97, 10371-10376.

(2) Haddad, K. C.; Sudmeier, J. L.; Bachovchin, D. A.; Bachovchin, W. W Proc. Natl Acad. Sci. U.S.A. 2005, 102, 1006-1011.

(3) Sigala, P. A.; Tsuchida, M. A.; Herschlag, D. Proc. Natl Acad. Sci. U.S.A. 2009, 106, 9232-9237.

(4) Fuhrmann, C. N.; Daugherty, M. D.; Agard, D. A. J. Am. Chem. Soc. 2006, 128, 9086-9102.

(5) Blakeley, M. P.; Langan, P.; Niimura, N.; Podjarny, A. Curr. Opin. Struct. Biol 2008, 18, 593-600.

(6) Plevin, M. J.; Hayashi, I.; Ikura, M. J. Am. Chem. Soc. 2008, 130, 14918-14919.
}

favorable cases. ${ }^{7}$ Out of the 20 amino acids commonly found in proteins, only three, namely, threonine, serine, and tyrosine, have a hydroxyl group. Often, hydroxyl groups are located on or near the surface of the protein and have been shown to be in rapid chemical exchange with the water of hydration at the surface of the protein..$^{8-10}$ Exchange rates are on the order of $50-1000 \mathrm{~s}^{-1}$ for serine and threonine and $1000-15000 \mathrm{~s}^{-1}$ for tyrosine, depending on temperature, the $\mathrm{pH}$ of the solution, and the presence of exchange catalysts. ${ }^{9,10}$ In the case where the hydroxyl proton is involved in a hydrogen bond, exchange rates are significantly reduced and the respective proton can serve then as a useful constraint in structure calculations.

The measurement of weak scalar couplings between two hydrogen-bonded nitrogen atoms $(\mathrm{N} \cdots \mathrm{H}-\mathrm{N})^{11-13}$ or between a carbonyl and an amide nitrogen $(\mathrm{CO} \cdots \mathrm{HN})^{12,14}$ is routinely exploited to unequivocally verify hydrogen bonds in solutionstate NMR. Analogous solution-state experiments involving two oxygen atoms are even more challenging $(\mathrm{CO} \cdots \mathrm{HO})$. Assignment of hydroxyl protons is therefore usually obtained via nuclear Overhauser spectroscopy ${ }^{15}$ or by analysis of HMBC experiments, ${ }^{16}$ which becomes difficult for larger spin systems.

(7) Hennig, M.; Fohrer, J.; Carlomagno, T. J. Am. Chem. Soc. 2005, 127, 2028-2029.

(8) Otting, G.; Liepinsh, E.; Wüthrich, K. Science 1991, 254, 974-980.

(9) Liepinsh, E.; Otting, G.; Wüthrich, K. J. Biomol. NMR 1992, 2, 447465.

(10) Liepinsh, E.; Otting, G. Magn. Res. Med. 1996, 35, 30-42.

(11) Dingley, A. J.; Grzesiek, S. J. Am. Chem. Soc. 1998, 120, 8293-8297.

(12) Cornilescu, G.; Hu, J.-S.; Bax, A. J. Am. Chem. Soc. 1999, 121, 29492950.

(13) Pervushin, K.; Ono, A.; Fernandez, C.; Szyperski, T.; Kainosho, M.; Wüthrich, K. Proc. Natl. Acad. Sci. U.S.A. 1999, 95, 14147-14151.

(14) Cordier, F.; Grzesiek, S. J. Am. Chem. Soc. 1999, 121, 1601-1602. 
In the solid state, the simultaneous presence of isotropic and anisotropic interactions allows great flexibility in the design of experimental methodologies. Anisotropic interactions are not averaged due to the tumbling of the molecule and can be employed for magnetization transfer. On one hand, it was demonstrated recently that scalar couplings across a hydrogen bond in the backbone of ubiquitine are accessible in the solidstate. ${ }^{17}$ On the other hand, measurement of dipolar couplings between quadrupolar nuclei allow one to estimate the bond length of medium-range hydrogen bonds $\left({ }^{17} \mathrm{O} \cdots \mathrm{H}^{17} \mathrm{O}\right) .{ }^{18-20}$ However, the enormous costs for labeling and the complexity of the method makes this approach cumbersome for practical applications such as proteins. One-bond ${ }^{1} \mathrm{H},{ }^{13} \mathrm{C}$ dipolar couplings are on the order of $20 \mathrm{kHz}$. Longer range correlations among nuclei that are not directly bonded are therefore feasible. ${ }^{21,22}$ Employing dipolar instead of scalar transfers allows one to transfer magnetization $>50$ times faster between directly bonded proton-carbon spin pairs. For spin pairs that are not directly bonded, the relative gain is even larger as scalar transfers involving ${ }^{2} J_{\mathrm{HC}}$ and ${ }^{3} J_{\mathrm{HC}}$ couplings $(\leq 5 \mathrm{~Hz}$ ) are very unfavorable. The respective dipolar coupling for a two-bond transfer is on the order of $3.7 \mathrm{kHz}$, corresponding to a ${ }^{1} \mathrm{H},{ }^{13} \mathrm{C}$ distance of $2.0 \AA$. HETCOR experiments have been used to assign hydroxyl protons and long-range methyl-amide proton correlations in a crystalline protein. ${ }^{23-26}$ In protonated samples, however, relayed ${ }^{1} \mathrm{H},{ }^{1} \mathrm{H}$ transfers during the proton spin-lock pulse in $\mathrm{CP}$ experiments can yield unspecific correlations. The heteronuclear dipolar transfer can be made selective by chemically eliminating the strong ${ }^{1} \mathrm{H}-{ }^{1} \mathrm{H}$ dipolar couplings by means of deuteration. We have shown recently that perdeuteration of proteins and recrystallization in a buffer containing varying amounts of $\mathrm{D}_{2} \mathrm{O}$ results in high-resolution MAS solid-state NMR spectra, ${ }^{27-29}$ which can be employed for solution-state-like correlation experiments such as 3D-HNCACB. ${ }^{30}$ Similarly, methyl protons can be employed for spectroscopy as commercially available ${ }^{2} \mathrm{H}$-glucose yields an incorporation of $-\mathrm{CHD}_{2}$ moieties that is on the order of $10 \% .^{31}$ The sensitivity of the experiments can

(15) Wagner, G. Q. Rev. Biophys. 1983, 16, 1-57.

(16) Bax, A.; Summers, M. F. J. Am. Chem. Soc. 1986, 108, 2093-2094.

(17) Schanda, P.; Huber, M.; Verel, R.; Ernst, M.; Meier, B. H. Angew. Chem. Int. Ed. 2009, 121, 9486-9489.

(18) van Beek, J. D.; Dupree, R.; Levitt, M. H. J. Magn. Reson. 2006, $179,38-48$

(19) Brinkmann, A.; Kentgens, A. P. M. J. Phys. Chem. B 2006, 110, 16089-16101.

(20) Brinkmann, A.; Kentgens, A. P. M. J. Am. Chem. Soc. 2006, 128, 14758-14759.

(21) van Rossum, B.-J.; Förster, H.; De Groot, H. J. M. J. Magn. Reson. 1997, 124, 516-519.

(22) van Rossum, B.-J.; de Groot, C. P.; Ladizhansky, V.; Vega, S.; de Groot, H. J. M. J. Am. Chem. Soc. 2000, 122, 3465-3472.

(23) Lesage, A.; Böckmann, A. J. Am. Chem. Soc. 2003, 125, 13336-13337.

(24) Böckmann, A.; Juy, M.; Bettler, E.; Emsley, L.; Galinier, A.; Penin, F.; Lesage, A. J. Biomol. NMR 2005, 32, 195-207.

(25) Lesage, A.; Emsley, L.; Penin, F.; Böckmann, A. J. Am. Chem. Soc. 2006, 128, 8246-8255.

(26) Lesage, A.; Gardiennet, C.; Loquet, A.; Verel, R.; Pintacuda, G.; Emsley, L.; Meier, B. H.; Bockmann, A. Angew. Chem. Int. Ed. 2008, 47, 5851-5854.

(27) Hologne, M.; Chevelkov, V.; Reif, B. Prog. NMR Spect. 2006, 48, 211-232.

(28) Chevelkov, V.; Rehbein, K.; Diehl, A.; Reif, B. Angew. Chem., Int. Ed. 2006, 45, 3878-3881.

(29) Akbey, Ü.; Lange, S.; Franks, T. W.; Linser, R.; Diehl, A.; Rossum, B.-J. v.; Reif, B.; Oschkinat, H. J. Biomol. NMR 2010, 46, 67-73.

(30) Linser, R.; Fink, U.; Reif, B. J. Magn. Reson. 2008, 193, 89-93.

(31) Agarwal, V.; Reif, B. J. Magn. Reson. 2008, 194, 16-24. be increased with precursors such as pyruvate ${ }^{32}$ or $\alpha$-ketoisovalerate. ${ }^{33}$ Alternatively, the recycle delay can be reduced by addition of chelated paramagnetic ions, like $\mathrm{Cu}$ (EDTA). ${ }^{34,35}$ The deuteration scheme enables an artifact-free quantification of the dynamic properties of a protein in the solid-state. ${ }^{36-40}$

In this work, we show that CP-based HETCOR experiments allow the observation of hydroxyl groups and their hydrogenbonding characteristics in a perdeuterated protein in the solidstate. We believe that these experiments will help us to better understand the role of hydroxyl groups in proton transfer reactions in enzymes and their thermodynamic role in protein stability. In addition, hydrogen bonds involving the backbone might help in the future to characterize the registry of the $\beta$-strand arrangement in amyloid fibrils.

\section{Material and Methods}

Identification of hydroxyl protons and characterization of their exchange behavior was done using a $\left[\mathrm{U}_{-}{ }^{2} \mathrm{H},{ }^{13} \mathrm{C},{ }^{15} \mathrm{~N}\right]$-labeled sample of the $\alpha$-spectrin SH3 domain, recrystallized from a buffer containing $\mathrm{D}_{2} \mathrm{O}$ and $\mathrm{H}_{2} \mathrm{O}$ in a ratio of $9: 1$. Backbone hydrogen bonding was studied using a $\left[\mathrm{U}-{ }^{2} \mathrm{H},{ }^{13} \mathrm{C},{ }^{15} \mathrm{~N}\right]$-labeled sample of the $\alpha$-spectrin SH3 domain, recrystallized from a buffer containing $\mathrm{D}_{2} \mathrm{O}$ and $\mathrm{H}_{2} \mathrm{O}$ in a ratio of $1: 1$. The sample preparation as well as the crystallization conditions were described previously. ${ }^{28}$ A detailed description of the employed NMR experiments and the integration procedure can be found in the Supporting Information.

\section{Results}

Correlation Spectroscopy. The ${ }^{13} \mathrm{C}$-detected ${ }^{1} \mathrm{H},{ }^{13} \mathrm{C}$ HETCOR spectrum shown yields intense cross peaks corresponding to correlations among amide protons and carbonyl and $\mathrm{C}^{\alpha}$ carbons, respectively. In addition, a few correlations among amide and methyl protons are observable. Methyl groups are fractionally protonated, as the precursors that are used for biosynthesis contain approximately $3 \%$ protons. ${ }^{31}$ Furthermore, correlations between aromatic carbon and downfield shifted proton resonances as well as to water are detected.

Hydroxyl proton resonances are unambiguously identified in HETCOR experiments that were recorded with decoupling in the indirect dimension, or by evolution of either the ${ }^{1} \mathrm{H},{ }^{13} \mathrm{C}$ and ${ }^{1} \mathrm{H},{ }^{15} \mathrm{~N}$ scalar couplings or both in $f_{1}$ (data not shown). Correlation signals originating from protons covalently bound to nitrogen or carbon are split into doublets while hydroxyl protons appear as singlets. The experiment represented in Figure 1 was recorded without ${ }^{13} \mathrm{C}$ decoupling in $f_{1}$. Singlet proton resonances are most intense for Tyr-C $\zeta$, Thr- $\mathrm{C} \beta$, and Ser-C $\beta$. Weaker signals are observed for correlations to remote carbon atoms in the same residue. The excellent dispersion in the ${ }^{1} \mathrm{H},{ }^{13} \mathrm{C}$ correlation is implied by the resolution in the proton dimension.

(32) Agarwal, V.; Diehl, A.; Skrynnikov, N.; Reif, B. J. Am. Chem. Soc. 2006, 128, 12620-12621.

(33) Agarwal, V.; Xue, Y.; Reif, B.; Skrynnikov, N. R. J. Am. Chem. Soc. 2008, 130, 16611-16621.

(34) Wickramasinghe, N. P.; Kotecha, M.; Samoson, A.; Past, J.; Ishii, Y. J. Magn. Reson. 2007, 184, 350-356.

(35) Linser, R.; Chevelkov, V.; Diehl, A.; Reif, B. J. Magn. Reson. 2007, 189, 209-216.

(36) Chevelkov, V.; Diehl, A.; Reif, B. Magn. Reson. Chem. 2007, 45, S156-S160.

(37) Chevelkov, V.; Diehl, A.; Reif, B. J. Chem. Phys. 2008, 128, 052316.

(38) Chevelkov, V.; Fink, U.; Reif, B. J. Am. Chem. Soc. 2009, 131, $14018-$ 14022.

(39) Krushelnitsky, A.; de Azevedo, E.; Linser, R.; Reif, B.; Saalwächter, K.; Reichert, D. J. Am. Chem. Soc. 2009, 131, 12097-12099.

(40) Chevelkov, V.; Fink, U.; Reif, B. J. Biomol. NMR 2009, 45, $197-$ 206. 


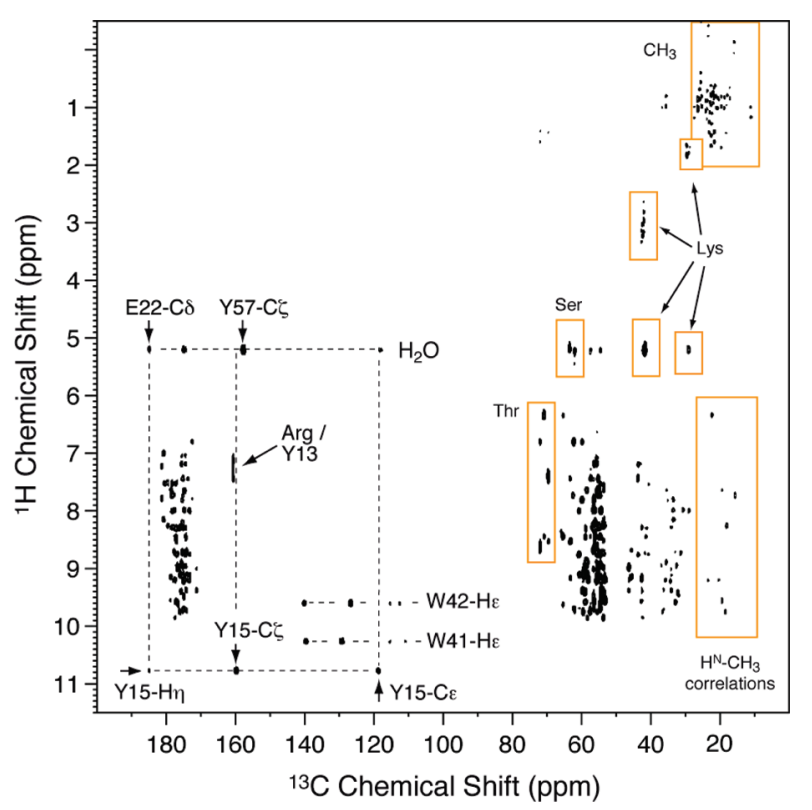

Figure 1. ${ }^{13} \mathrm{C}$ detected ${ }^{1} \mathrm{H},{ }^{13} \mathrm{C}$ correlation experiment using long-range $\mathrm{CP}$ for magnetization transfer $\left(\tau_{\mathrm{CP}}=2.2 \mathrm{~ms}\right)$. The experiment was recorded using a sample of perdeuterated $\alpha$-spectrin $\mathrm{SH} 3\left(90 \% \mathrm{D}_{2} \mathrm{O}\right.$ in the crystallization buffer). A $180^{\circ}$ pulse on ${ }^{15} \mathrm{~N}$ was used to eliminate ${ }^{1} \mathrm{H}-{ }^{15} \mathrm{~N}$ scalar couplings in the $f_{1}$ dimension, while WALTZ-16 was used to decouple ${ }^{15} \mathrm{~N},{ }^{13} \mathrm{C}$ and ${ }^{2} \mathrm{H},{ }^{13} \mathrm{C}$ scalar couplings in $f_{2}$. The spectrum was recorded at an effective temperature of $5{ }^{\circ} \mathrm{C}$. The excellent resolution in the ${ }^{1} \mathrm{H}$ dimension yields well-resolved $\mathrm{H}^{\mathrm{N}}-\mathrm{CO}$ and $\mathrm{H}^{\mathrm{N}}-\mathrm{C}^{\alpha}$ correlations.

A number of correlations are observed between carbon resonances of the protein and the water chemical shift. However, no deviations from the bulk water resonance frequency are detected, which is in contrast to what has been observed previously. ${ }^{41}$ The most intense correlation at the water frequency is found for lysine side chain resonances. Apparently, these correlations are not mediated via dipolar couplings but are rather due to rapid chemical exchange between the lysine side chain $\mathrm{NH}_{3}{ }^{+}$protons and bulk water, ${ }^{23,24,42}$ as all peaks at the water frequency involve an exchangeable proton in the vicinity of the observed carbon resonance. The $\alpha$-spectrin SH3 domain has six lysine residues. Due to a lack in dispersion in the Lys-C $\delta$ and $-\mathrm{C} \varepsilon$ chemical shifts, it is difficult to unambiguously state how many lysine side chains are involved in chemical exchange. We speculate that the smaller gyromagnetic ratio of carbons (in comparison to protons) prevents the observation of dipolar transfers. ${ }^{43}$ Resonances appearing at the water frequency are assigned as Lys-C $\delta$, Lys-C $\varepsilon$, Ser19-C $\alpha$ Ser36-C $\alpha$, Ser36-C $\beta$, Ser19-C $\beta$, Tyr57-C $\varepsilon$, Tyr57-C $\xi$, and Glu22-C $\delta$ (from high to low field in the carbon dimension). The resonance at $178 \mathrm{ppm}$ could not be assigned and is most likely due to an aspartic acid carboxylic carbon.

The spectral region involving threonine proton and carbon resonances is shown in Figure 2. The SH3 domain contains four threonine residues, T4, T24, T32, and T37. T4 is located in the flexible N-terminus of the protein and its resonances are filtered during the $\mathrm{CP}$ contact period. HETCOR spectra recorded at two

(41) Böckmann, A.; Gardiennet, C.; Verel, R.; Hunkeler, A.; Loquet, A.; Pintacuda, G.; Emsley, L.; Meier, B. H.; Lesage, A. J. Biomol. NMR 2009, 45, 319-327.

(42) Harbison, G. S.; Roberts, J. E.; Herzfeld, J.; Griffin, R. G. J. Am. Chem. Soc. 1988, 110, 7221-7223.

(43) Chevelkov, V.; Faelber, K.; Diehl, A.; Heinemann, U.; Oschkinat, H.; Reif, B. J. Biomol. NMR 2005, 31, 295-310.

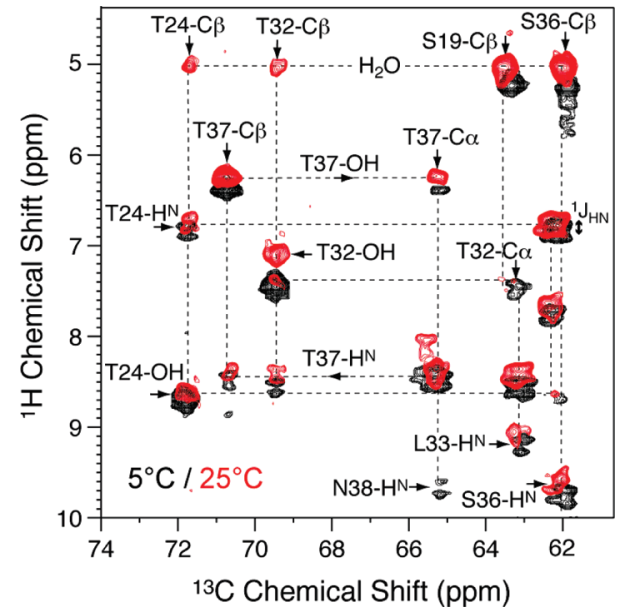

Figure 2. ${ }^{13} \mathrm{C}$ detected HETCOR focusing on the threonine spectral region. The spectrum was recorded at $5{ }^{\circ} \mathrm{C}$ (black) and $25{ }^{\circ} \mathrm{C}$ (red). Experiments were acquired without ${ }^{15} \mathrm{~N}$ decoupling in the proton dimension. Correlations involving amide protons are therefore split into doublets.

effective temperatures, 5 and $25^{\circ} \mathrm{C}$, are represented in black and red, respectively. All threonine residues have distinct $\mathrm{H} \gamma 1$ chemical shifts and do not exchange with water at low temperatures during the $\mathrm{CP}$ mixing time. At $5{ }^{\circ} \mathrm{C}$, the hydroxyl proton of T24 (T24-OH) has a chemical shift of $8.5 \mathrm{ppm}$. According to the BMRB database, the chemical shift range for Thr-H $\gamma 1$ covers the spectral region from 0.32 to $8.21 \mathrm{ppm}$. The average chemical shift of $\mathrm{H} \gamma 1$ corresponds to $5.09 \pm 1.44 \mathrm{ppm}$. T24-OH is downfield shifted compared to the average chemical shift of $\mathrm{H} \gamma 1$, which is indicative of a hydrogen-bonded proton. T32-OH and T37-OH show a proton chemical shift of $7.25 \mathrm{ppm}$ and $6.20 \mathrm{ppm}$, respectively. Other correlations in the spectrum are due to intraresidue correlations involving the amide proton. Threonine $\mathrm{OH}-$ methyl correlations are as well observable (see Supporting Information). These correlations are, however, weaker as the distance between the hydroxyl proton and the methyl group is longer (ca. $3.2 \AA$ ) and dependent on the $\mathrm{H}-\mathrm{O}-\mathrm{C}-\mathrm{X}$ torsional angle, in comparison to the distance between the hydroxyl proton and $\mathrm{C} \beta$ (ca. $2.0 \AA$ ) which is only dependent on the $\mathrm{H}-\mathrm{O}-\mathrm{C} \beta$ angle. An increase of the temperature shows that the chemical shift of T32-OH is highly sensitive to temperature variations, whereas $\mathrm{T} 24-\mathrm{OH}$ and $\mathrm{T} 37-\mathrm{OH}$ are insensitive or at best weakly sensitive to temperature changes. At $25^{\circ} \mathrm{C}$, correlations involving $\mathrm{T} 24-\mathrm{C} \beta$ and $\mathrm{T} 32-\mathrm{C} \beta$ show an additional peak at the water frequency, while the distinct hydroxyl chemical shift is retained.

S19 and S36 are the only two serine residues in the protein. At $5{ }^{\circ} \mathrm{C}, \mathrm{S} 19-\mathrm{OH}-\mathrm{C} \beta$ is found to coincide with the water frequency, while $\mathrm{S} 36-\mathrm{OH}$ is downfield shifted by about $18 \mathrm{~Hz}$ $(0.025 \mathrm{ppm})$ on a $700 \mathrm{MHz}$ spectrometer. Apparently, the serine hydroxyl proton chemical shift overlaps with the bulk water resonance. Serine and threonine side chains are chemically very similar and were shown to have almost identical exchange properties. ${ }^{10}$ We therefore assume that the observed cross peak is due to magnetization transfer between $\operatorname{Ser}-\mathrm{C} \beta$ and its hydroxyl proton. We cannot totally rule out the possibility of an exchangemediated cross peak with water. However, variable temperature experiments show differences in the behavior of the two hydroxyl protons. At $-4{ }^{\circ} \mathrm{C}$ (frozen sample, data not shown), no $\mathrm{S} 19-\mathrm{OH}-\mathrm{C} \beta$ correlation is observed, while $\mathrm{S} 36-\mathrm{OH}-\mathrm{C} \beta$ shows a broad shoulder downfield of the water resonance. 


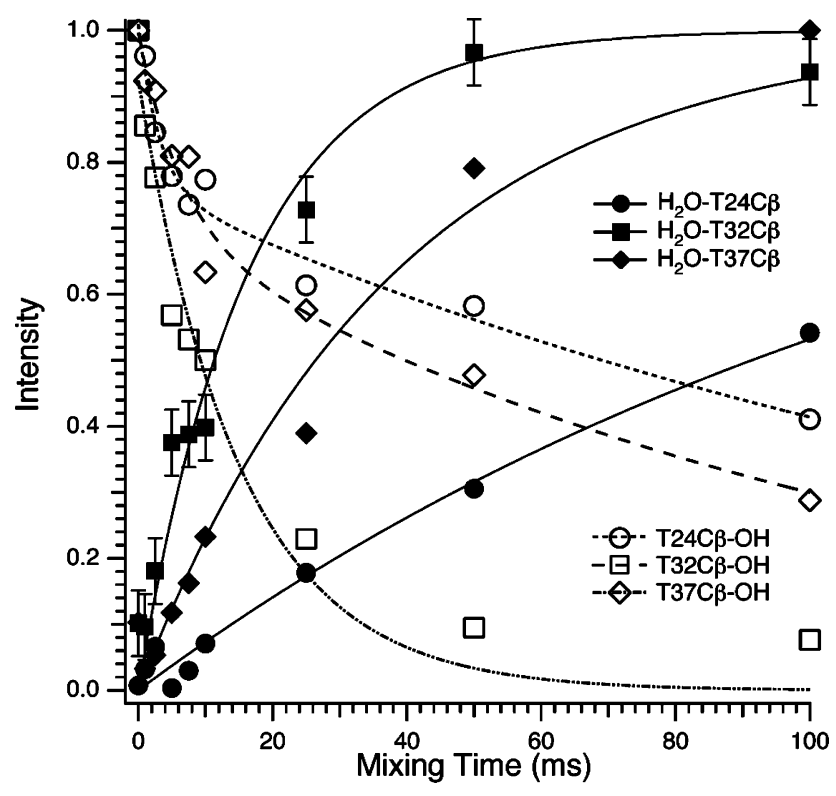

Figure 3. Hydroxyl proton exchange for T24, T32, and T37 in perdeuterated $\alpha$-spectrin SH3. Open symbols represent the decay of the Thr$\mathrm{H} \gamma 1-\mathrm{C} \beta$ cross peak intensity due to exchange, while closed symbols correspond to the buildup of the $\mathrm{HDO}-\mathrm{Thr}-\mathrm{C} \beta$ cross peak. Error bars are shown only for the buildup of magnetization for the correlation HDO-T32$\mathrm{C} \beta$ and refer to the noise rms in the respective spectrum.

Y13, Y15, and Y57 are the three polar aromatic residues present in the $\alpha$-spectrin SH3 domain. The tyrosine hydroxyl protons are assigned in Figure 1. Y15-OH, with a chemical shift of $10.5 \mathrm{ppm}$, is the most downfield shifted proton resonance in this protein and is easily identified even in a ${ }^{1} \mathrm{H}-1 \mathrm{D}$ spectrum. For all employed temperatures, Y57-OH shows only a correlation signal to water. Y13-OH cannot be unambiguously assigned, as $\mathrm{Y} 13-\mathrm{C} \xi$ is superimposed with the arginine $\mathrm{C} \xi$ chemical shift. In the BMRB database, tyrosine hydroxyl protons are found in the chemical shift range from 5.99 to $13.75 \mathrm{ppm}$, with an average of $9.33 \pm 1.47 \mathrm{ppm}$. Variable temperature experiments indicate that the $\mathrm{Y} 15-\mathrm{OH}$ chemical shift is weakly susceptible to temperature changes (data not shown). At $25^{\circ} \mathrm{C}$, the intensity of the Y15 hydroxyl resonance (10.5 ppm) decreases and a peak at the water frequency appears, corresponding to the correlation $\mathrm{HDO}-\mathrm{Y} 15-\mathrm{C} \zeta$.

Quantification of Threonine Hydroxyl Exchange Rates. Chemical exchange processes can be investigated using twodimensional homonuclear exchange experiments. ${ }^{44}$ Tyrosine hydroxyl exchange rates have been quantified recently in solution-state NMR making use of the deuterium isotopic effect on the $\mathrm{C}-\zeta$ chemical shift. ${ }^{45}$ In our experiment (Figure 1 of the Supporting Information), the ${ }^{1} \mathrm{H},{ }^{13} \mathrm{C} \mathrm{CP}$ transfer is preceded by a longitudinal mixing period, during which exchange can occur. In the experiment, the initial magnetization is originating from protons, as proton spin-lattice relaxation times are sufficiently short to allow for short recycle delays.

Figure 3 shows the decay and the buildup profile of all $\mathrm{Thr}-$ $\mathrm{OH}-\mathrm{C} \beta$ and $\mathrm{HDO}-\mathrm{Thr}-\mathrm{C} \beta$ correlations obtained as a function of the exchange mixing time. In general, the rates for the decay of the hydroxyl resonance intensity and the buildup of the cross peak to water are very similar, indicating that proton spin diffusion is not playing an important role. However, the Thr-

(44) Jeener, J.; Meier, B. H.; Bachmann, P.; Ernst, R. R. J. Chem. Phys. 1979, 71, 4546-4553.
Table 1. Threonine Hydroxyl Proton Exchange Rates in the Microcrystalline $\alpha$-Spectrin SH3 Domain $\left(\mathrm{pH} 7.2, T=5^{\circ} \mathrm{C}\right)^{a}$

\begin{tabular}{|c|c|c|c|c|}
\hline \multirow[b]{2}{*}{ residue } & \multicolumn{3}{|c|}{ Thr- $\mathrm{H} \gamma 1-\mathrm{C} \beta\left(\mathrm{s}^{-1}\right)$} & \multirow{2}{*}{$\begin{array}{c}\mathrm{HDO}-\mathrm{Thr}-\mathrm{C} \beta\left(\mathrm{s}^{-1}\right) \\
\mathrm{k}_{\mathrm{OH}-\mathrm{H}_{2} \mathrm{O}}+k_{\mathrm{cl}} \\
\end{array}$} \\
\hline & {$\left[\mathrm{OH}_{\text {closed }}\right] /\left[\mathrm{OH}_{\text {open }}\right]$} & $k_{\mathrm{op}}$ & $\mathrm{K}_{\mathrm{OH}-\mathrm{H}_{2} \mathrm{O}}$ & \\
\hline $\mathrm{T} 24$ & $3.0 \pm$ & $6.1 \pm 1.0$ & $323 \pm 140$ & $7.6 \pm 0.4$ \\
\hline T32 & $2.2 \pm 0.4$ & $39.5 \pm 8.8$ & $381 \pm 229$ & $61.4 \pm 6.6$ \\
\hline T37 & $2.3 \pm 0.3$ & $8.5 \pm 2.5$ & $154 \pm 87$ & $26.3 \pm 2.6$ \\
\hline
\end{tabular}

${ }^{a}$ Exchange of Thr-H $\gamma 1$ is following a biexponential behavior, whereas the sensitivity for the $\mathrm{HDO}-\mathrm{Thr}-\mathrm{C} \beta$ cross peak buildup allows only monoexponential fitting.

$\mathrm{OH}-\mathrm{Thr}-\mathrm{C} \beta$ magnetization decay curves do not fit a monoexponential decay very well. A more involved model takes the opening of the hydrogen bond into account ${ }^{46-48}$

$$
\mathrm{OH}_{\text {closed }} \underset{k_{\mathrm{cl}}}{\stackrel{k_{\mathrm{op}}}{\rightleftharpoons}} \mathrm{OH}_{\text {open }} \stackrel{k_{\mathrm{OH}-\mathrm{H}_{2} \mathrm{O}}}{\rightleftharpoons} \mathrm{H}_{2} \mathrm{O}
$$

The observation of a single hydroxyl resonance is consistent with this scheme, in the case where the opening and closing of the hydrogen bond is fast on the NMR time scale. The respective differential equation can be written as

$$
\begin{aligned}
& \frac{\mathrm{d}}{\mathrm{d} t}\left[\begin{array}{c}
M\left(\mathrm{OH}_{\mathrm{cl}}\right) \\
M\left(\mathrm{OH}_{\mathrm{op}}\right) \\
M\left(\mathrm{H}_{2} \mathrm{O}\right)
\end{array}\right]= \\
& \left(\begin{array}{ccc}
-R_{1}^{\mathrm{cl}}-k_{\mathrm{op}} & +k_{\mathrm{cl}} & 0 \\
+k_{\mathrm{op}} & -R_{1}^{\mathrm{op}}-k_{\mathrm{cl}}-k_{\mathrm{OH}-\mathrm{H}_{2} \mathrm{O}} & 0 \\
0 & +k_{\mathrm{OH}-\mathrm{H}_{2} \mathrm{O}} & -R_{1}^{\mathrm{H}_{2} \mathrm{O}}
\end{array}\right)\left[\begin{array}{c}
M\left(\mathrm{OH}_{\mathrm{cl}}\right) \\
M\left(\mathrm{OH}_{\mathrm{op}}\right) \\
M\left(\mathrm{H}_{2} \mathrm{O}\right)
\end{array}\right]
\end{aligned}
$$

In the analysis, it is assumed that the longitudinal relaxation rates $R_{1}^{\mathrm{cl}}, R_{1}^{\mathrm{op}}$, and $R_{1}^{\mathrm{H}_{2} \mathrm{O}}$ are negligible compared to the respective exchange rates and are omitted in the fit. This assumption seems reasonable as ${ }^{1} \mathrm{H} R_{1}$ rates in the absence of a paramagnetic doping reagent are smaller than $0.5 \mathrm{~s}^{-1}{ }^{49}$ Table 1 contains the respective hydroxyl proton exchange rates for threonine residues in the microcrystalline $\alpha$-spectrin SH3 domain at a $\mathrm{pH}$ value of 7.2 and a temperature of $5{ }^{\circ} \mathrm{C}$.

The experimental exchange rates $k_{\mathrm{OH}-\mathrm{H}_{2} \mathrm{O}}$ correspond rather well to the intrinsic hydroxyl proton exchange rates that have been reported by Liepinsh and Otting for isolated amino acids in aqueous buffer at this particular $\mathrm{pH}$ value and temperature. ${ }^{10}$ Interestingly, the $k_{\mathrm{OH}-\mathrm{H}_{2} \mathrm{O}}$ exchange rate for T37 is a factor of 2 smaller compared to that of T24 and T32. T37 is the only threonine that is not in the vicinity of a carboxylic group in the structure of the $\alpha$-spectrin SH3 domain (Figure 7). We speculate that the enhanced $k_{\mathrm{OH}-\mathrm{H}_{2} \mathrm{O}}$ rate observed for $\mathrm{T} 24$ and $\mathrm{T} 32$ is due to an acid/base-catalyzed exchange mechanism. ${ }^{50}$ In agreement with our observation, Liepinsh and Otting demonstrated that the hydroxyl exchange rate of acetyl-threonine- $\mathrm{OCH}_{3}$ is increased by approximately a factor of 50 in the presence of 50 $\mathrm{mM}$ acetate. Exchange rates $k_{\mathrm{op}}$ for T32 are fast compared to those of T24. T37 shows an intermediate behavior. Differences

(45) Takeda, M.; Jee, J.; Ono, A. M.; Terauchi, T.; Kainosho, M. J. Am. Chem. Soc. 2009, 131, 18556-18562.

(46) Farrow, N. A.; Zhang, O.; Forman-Kay, J. D.; Kay, L. E. J. Biomol. NMR 1994, 4, 727-734.

(47) Jardetzky, O.; Finucane, M. D. Mol. Phys. 1998, 95, 1127-1136.

(48) Mao, X.-A.; Zhang, Y.-H. Magn. Reson. Chem. 2001, 13, 326-333.

(49) Linser, R.; Fink, U.; Reif, B. J. Am. Chem. Soc. 2009, 131, 1370313708. 


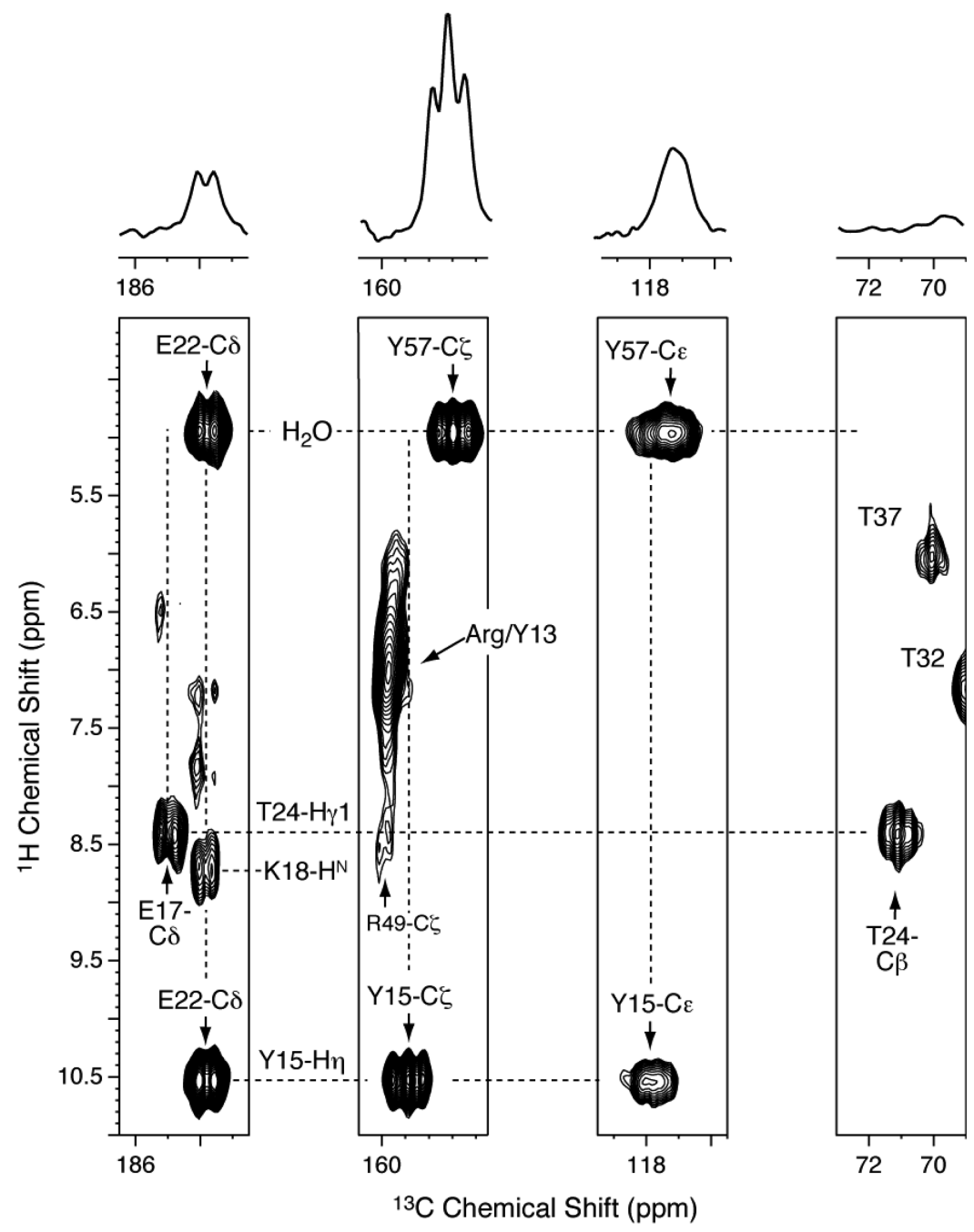

Figure 4. ${ }^{13} \mathrm{C}$-detected ${ }^{1} \mathrm{H},{ }^{13} \mathrm{C}$ correlation, highlighting specific correlations between hydroxyl and carboxylic groups in $\alpha$-spectrin SH3. The spectrum was recorded at a temperature of $5{ }^{\circ} \mathrm{C}$. The $1 \mathrm{D}$ spectrum on top of the figure displays the ${ }^{13} \mathrm{C}$ row taken at the water chemical shift.

in the hydroxyl exchange rates are in agreement with the X-ray structure: The hydroxyl group of T24 is involved in a side chain hydrogen bond to the carboxylic group of E17 (see below). On the other hand, T32 is exposed to the solvent and T37-OH is in hydrogen bonding distance to the side chain amino group of N38. In analogy to the magnetization decay of the ThrOHThrC $\beta$ cross peak, a biexponential behavior would be expected as well for the HDO-Thr-C $\beta$ buildup. However, the sensitivity for short EXSY mixing times is not sufficient to support a twoparameter fit. Normalization of the data might be another potential problem. Intensities of the buildup curves in Figure 3 are calibrated using the cross peak intensity HDO-Thr32C $\beta$ $\left(\tau_{\text {mix }}=100 \mathrm{~ms}\right)$ as a reference. We therefore speculate that higher quality data would be required to observe a biexponential buildup behavior for HDO-ThrC $\beta$ cross peaks.

Side Chain Hydrogen Bonds. Side chain hydrogen bonds usually involve polar residues such as Glu, Asp, Thr, Ser, or Tyr. The $\mathrm{H} \cdots$ Y distance in an $\mathrm{X}-\mathrm{H} \cdots \mathrm{Y}$ hydrogen bond is on the order of 1.5-3.0 $\AA$. Hydrogen bonds with $\mathrm{H} \cdots \mathrm{Y}$ distances of $1.2-1.5,1.5-2.2$, and $2.2-3.0 \AA$ are classified as strong, medium, and weak hydrogen bonds, respectively. ${ }^{51,52}$ The

(50) Eigen, M. Angew. Chem. 1963, 12, 489-588.

(51) Jeffrey, G. A.; Saenger, W. Hydrogen Bonding in Biological Structures; Springer: Berlin, 1991.
HETCOR experiment can be used to identify hydrogen bonds of the type $\mathrm{C}=\mathrm{O} \cdots \mathrm{HO}-\mathrm{C}$ in protein side chains. In the $\mathrm{SH} 3$ domain, we observe at least three such side chain hydrogen bonds. For $\mathrm{Y} 15-\mathrm{H} \eta$, we find correlations to the carbon resonances $\mathrm{Y} 15-\mathrm{C} \zeta$, $-\mathrm{C} \varepsilon$, and E22-C $\delta$, respectively (Figure 4). The assignment of this hydrogen bond is simple, as all involved ${ }^{1} \mathrm{H}$ and ${ }^{13} \mathrm{C}$ chemical shifts are well-resolved. Similarly, we find a correlation between $\mathrm{T} 24-\mathrm{H} \gamma 1$ and T24-C $\beta 1$ as well as to E17$\mathrm{C} \delta$. Finally, the resonance T37-H $\gamma 1$ shows a cross peak to T37$\mathrm{C} \beta$ and to $\mathrm{N} 35-\mathrm{C} \gamma$ (data not shown). In the X-ray structure, we find $\mathrm{O} \cdots \mathrm{O}$ distances of $2.58,2.65$, and $2.76 \AA$ for the hydrogen bonds involving Y15-E22, T24-E17, and T37-N35, respectively (PDB code 2NUZ). ${ }^{53}$ The $\mathrm{O} \cdots \mathrm{O}$ distance information is, however, not sufficient to assign a hydrogen bond, as the van der Waals $\mathrm{O} \cdots \mathrm{O}$ distances $(2.8 \AA)$ is in the same range as the $\mathrm{O} \cdots \mathrm{O}$ distance in a $\mathrm{O}-\mathrm{H} \cdots \mathrm{O}$ hydrogen bond. ${ }^{54}$

The HETCOR experiment reveals the proximity of a proton to a hydrogen-bond acceptor, but it does not allow one to exactly localize the proton in the hydrogen bond. In principle, the position of the proton in the spin system ${ }^{13} \mathrm{C}=\mathrm{O} \cdot \cdots \mathrm{HO}-{ }^{13} \mathrm{C}$

(52) Parthasarathi, R.; Subramanian, V. Hydrogen Bonding-New Insights; Springer: Berlin, 2006; Vol. 3, pp 1-50.

(53) Chevelkov, V.; Faelber, K.; Schrey, A.; Rehbein, K.; Diehl, A.; Reif, B. J. Am. Chem. Soc. 2007, 129, 10195-10200. 
A)

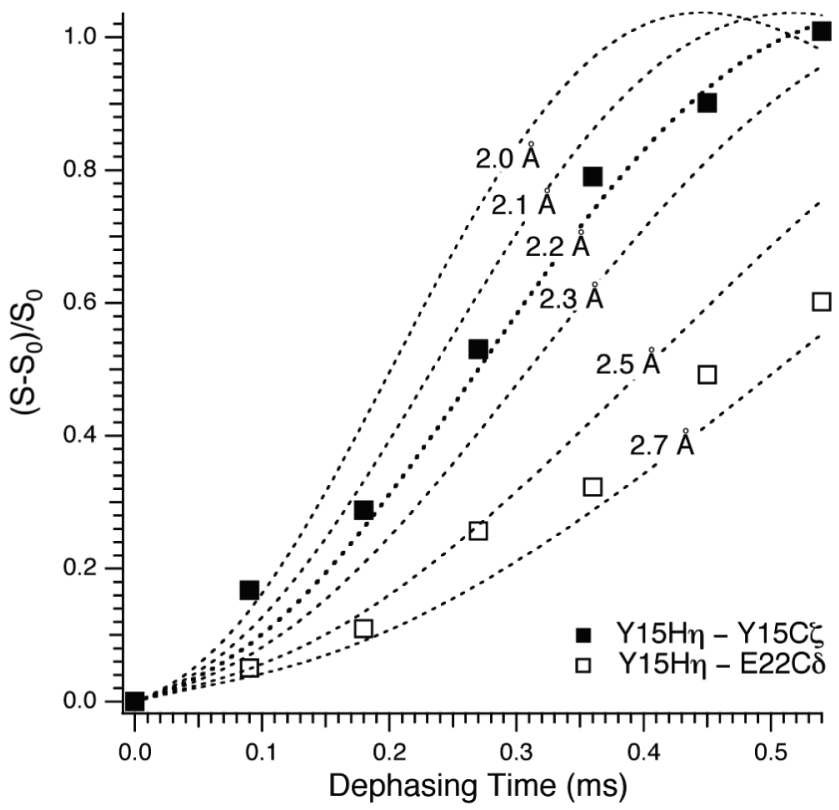

B)

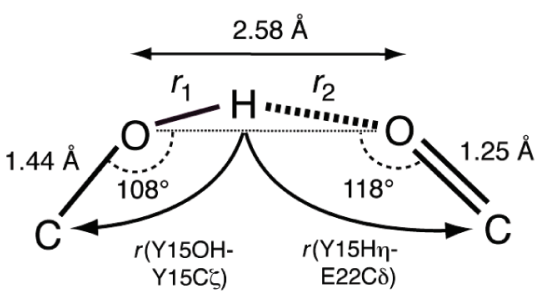

C)

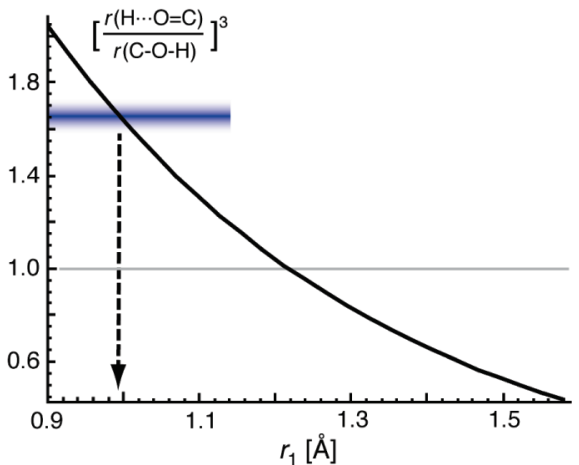

Figure 5. (A) ${ }^{1} \mathrm{H},{ }^{13} \mathrm{C}$ REDOR dephasing profile for $\mathrm{Y} 15-\mathrm{H} \eta-\mathrm{Y} 15-\mathrm{C} \xi$ and $\mathrm{Y} 15-\mathrm{H} \eta-\mathrm{E} 22-\mathrm{C} \delta$ (filled and open squares) in the $\alpha$-spectrin $\mathrm{SH} 3$ domain. Data are represented as $\left(S-S_{0}\right) / S_{0}$, where $S$ and $S_{0}$ correspond to the integral intensity of the REDOR and the reference experiment, respectively. The employed pulse program is represented as part of the Supporting Information. Dashed lines represent two-spin simulations in which the ${ }^{1} \mathrm{H},{ }^{13} \mathrm{C}$ dipolar coupling is systematically varied by assuming ${ }^{1} \mathrm{H},{ }^{13} \mathrm{C}$ distances between 2.0 and $2.7 \AA$. Simulations were carried out using the program SIMPSON. ${ }^{55}$ (B) Schematic representation of the geometry of the $\mathrm{C}=\mathrm{O} \cdots \mathrm{HO}-\mathrm{C}$ hydrogen bond. In order to extract the distances between the hydroxyl proton to the threonine $\mathrm{C} \beta$ and the carbonyl atom, respectively, we assume standard bond lengths and geometries. ${ }^{56}$ (C) Calculated ratio of the experimental dipolar couplings as a function of the $\mathrm{OH}$ bond length $r_{1}$ determined for the hydrogen bond Y15-E22.

can be estimated by quantification of the dipolar couplings between the proton and the respective carbon atoms. The measured buildup rate is related to the distance between the two involved nuclei via the equation

$$
D_{\mathrm{CH}}=\frac{\mu_{0}}{4 \pi} \frac{\gamma_{\mathrm{H}} \gamma_{\mathrm{C}} \hbar}{r_{\mathrm{CH}}{ }^{3}}
$$

We attempted to determine dipolar couplings via CP-based experiments, ${ }^{38}$ but with limited success. While the CP curve (data not shown) indicates the expected qualitative buildup of magnetization as a function of mixing time, it does not show any dipolar oscillations. These experiments have been carried out using a perdeuterated protein sample recrystallized from $50 \%$ $\mathrm{H}_{2} \mathrm{O}$. We speculate that proton-proton dipolar mixing during the proton spin-lock might compromise the heteronuclear magnetization transfer. On the other hand, the same experiments carried out for a sample crystallized from $10 \% \mathrm{H}_{2} \mathrm{O}$ did not yield enough sensitivity to quantitate the magnetization buildup properly.

Alternatively, the distance between the hydroxyl proton and the carbon atom in the donor and the acceptor group, respectively, is measured using a REDOR experiment. ${ }^{57}$ Figure 5 shows the REDOR buildup curve. The employed pulse sequence is represented in Figure 4 of the Supporting Information. In order to extract the distances $r_{1}$ and $r_{2}$ (Figure 5B), we assume standard bond lengths and geometries. ${ }^{56,58-60}$ Planarity is not required as the measured distances $r_{1}$ and $r_{2}$ are invariant with respect to rotations around the torsional angles $\mathrm{X}-\mathrm{C}-\mathrm{O}-\mathrm{H}$ and

(54) Saenger, W. Annu. Rev. Biophys. Biophys. Chem. 1987, 16, 93-114.
$\mathrm{H} \cdots \mathrm{O}=\mathrm{C}-\mathrm{X}$. Taking the $\mathrm{O} \cdots \mathrm{O}$ distance as given from the $\mathrm{X}$-ray structure, the relative buildup rates in the REDOR experiment allow one to extract $r_{1}$. Alternatively, the $\mathrm{O} \cdots \mathrm{O}$ distance can be approximated by making use of the hydroxyl proton chemical shift. ${ }^{61-63}$ Figure $5 \mathrm{C}$ represents the calculated ratio of the experimental dipolar couplings as a function of the $\mathrm{OH}$ bond length $r_{1}$ determined for the hydrogen bond Y15E22. In the simulation, an $\mathrm{O}-\mathrm{H} \cdots \mathrm{O}$ angle of $160^{\circ}$ is assumed. ${ }^{59}$ Experimentally, we find a ratio of dipolar couplings $[r(\mathrm{H} \cdots \mathrm{O}=\mathrm{C}) /$ $r(\mathrm{C}-\mathrm{O}-\mathrm{H})]^{3}=1.65$. This is in agreement with a $\mathrm{OH}$ bond length $r_{1}$ on the order of $1.0 \AA$. The isotropic chemical shift of Tyr15-H $\eta$ assumes a value of $10.5 \mathrm{ppm}$. Independent of any geometric assumptions, the relative cross peak intensity $\mathrm{CP}(\mathrm{C}-\mathrm{O}-\mathrm{H}) / \mathrm{CP}(\mathrm{H} \cdots \mathrm{O}=\mathrm{C})$ is an indicator that allows one to differentiate if the hydroxyl proton is closer to the donor or the acceptor chemical group. A systematic investigation involving NMR experimental data and structural information from X-ray and neutron crystallography, as well as quantum chemical calculations, suggests a value for $r_{1}$ of $1.0 \AA$ for this particular proton chemical shift. ${ }^{64} \mathrm{We}$ expect that the experimental

(55) Bak, M.; Rasmussen, J. T.; Nielsen, N. C. J. Magn. Reson. 2000, 147, 296-330.

(56) Frey, M. N.; Lehmann, M. S.; Koetzle, T. F.; Hamilton, W. C. Acta Crystallogr. B 1973, 29, 876-884.

(57) Gullion, T.; Schaefer, J. Adv. Magn. Reson. 1989, 13, 57-83.

(58) Burgi, H. B.; Dunitz, J. D. Acc. Chem. Res. 1983, 16, 153-161.

(59) Steiner, T.; Saenger, W. Acta Crystallogr. 1994, B50, 348-357.

(60) Steiner, T. Angew. Chem. Int. Ed. 2002, 41, 48-76.

(61) McDermott, A. E.; Ridenour, C. F. Proton Chemical Shift Measurements in Biological Solids. In Encyclopedia of NMR; Grant, D. M.; Harris, R. K., Eds.; Wiley: Sussex, England, 1996; pp 3820-3825.

(62) Harris, T. K.; Zhao, Q.; Mildvan, A. S. J. Mol. Struct. 2000, 552, 97-109. 
A)

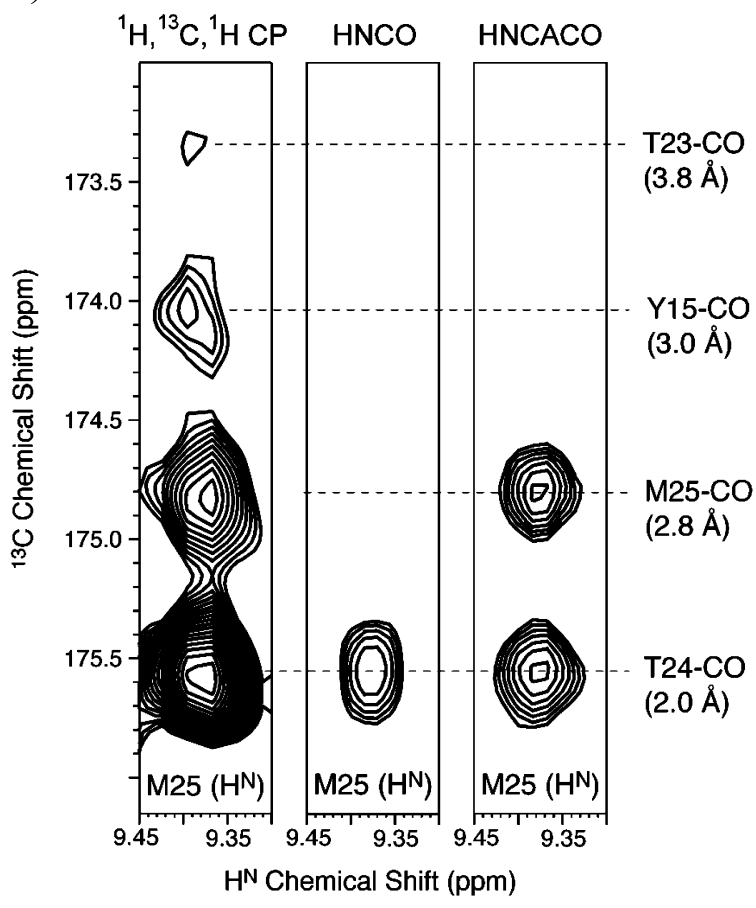

B)

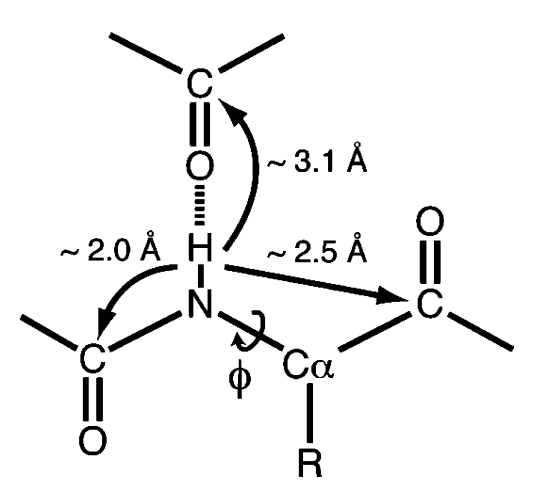

Figure 6. ${ }^{1} \mathrm{H}$-detected ${ }^{1} \mathrm{H}-{ }^{13} \mathrm{C}$ correlation spectrum recorded using the pulse sequence shown in Figure 3 of the Supporting Information. In order to probe long-range transfers, the $\mathrm{CP}$ contact time was set to $10 \mathrm{~ms}$. We find inter- and intraresidual $\mathrm{H}^{\mathrm{N}}-\mathrm{CO}$ correlations, as well as correlations across the backbone hydrogen bond. Assignments are confirmed using HNCO- and HNCACO-type experiments.

localization of the hydroxyl proton in a hydrogen bond will facilitate the quantification of noncovalent interactions, which so far relies mostly on proton chemical shift information and DFT calculations. ${ }^{64,65}$

Hydrogen Bonds across $\boldsymbol{\beta}$-Strands. An obvious application of the proposed methodology is the characterization of backbone hydrogen bonding involving adjacent $\beta$-strands. An unambiguous characterization involves the measurement of scalar couplings among a carbonyl and an amide nitrogen across the hydrogen bond. ${ }^{14}$ For small organic molecules, it was shown that scalar-coupling-based experiments are feasible in the solid state. ${ }^{66-68}$ For proteins, this approach is difficult due to the small size of the involved scalar coupling $(<1 \mathrm{~Hz})$. Nevertheless, it could be demonstrated recently that scalar couplings across hydrogen bonds can be measured for a crystalline sample of ubiquitin. ${ }^{17}$ By contrast, $\mathrm{NH}-\mathrm{HN} / \mathrm{NH}-\mathrm{HC}$ - and $\mathrm{CH}-\mathrm{HC}$-type experiments ${ }^{69,70}$ have been used in the past to elucidate the protein fold. The experiments rely on dipolar transfers among protons that are close in space. This method was recently used to identify hydrogen bonds in fibrils of the prion-forming domain

(63) Mildvan, A. S.; Massiah, M. A.; Harris, T. K.; Marks, G. T.; Harrison, D. H. T.; Viragh, C.; Reddy, P. M.; Kovach, I. M. J. Mol. Struct. 2004, 615, 163-175.

(64) Limbach, H.-H.; Tolstoy, P. M.; Pérez-Hernández, N.; Guo, J.; Shenderovich, I. G.; Denisov, G. S. Isr. J. Chem. 2009, 49, 199-216.

(65) Tolstoy, P. M.; Limbach, H.-H. J. Am. Chem. Soc. 2004, 126, 56215634.

(66) Brown, S. P.; Perez-Torralba, M.; Sanz, D.; Claramunt, R. M.; Emsley, L. J. Am. Chem. Soc. 2002, 124, 1152-1153.

(67) Brown, S. P.; Perez-Torralba, M.; Sanz, D.; Claramunt, R. M.; Emsley, L. Chem. Commun. 2002, 17, 1852-1853.

(68) Yates, J. R.; Pham, T. N.; Pickard, C. J.; Mauri, F.; Amado, A. M.; Gil, A. M.; Brown, S. P. J. Am. Chem. Soc. 2005, 127, 10216-10220.

(69) Lange, A.; Luca, S.; Baldus, M. J. Am. Chem. Soc. 2002, 124, 9704 9705 . of HET-s. ${ }^{71}$ Alternatively, dipolar correlations between the amide proton and the carbonyl of the hydrogen-bond acceptor $\left(\mathrm{N}-{ }^{1} \mathrm{H} \cdot \cdots \mathrm{O}-{ }^{13} \mathrm{C}\right)$ can be exploited. The distance between $\mathrm{H}^{\mathrm{N}}$ and $\mathrm{CO}_{i-1} / \mathrm{CO}_{i}$ are on the order of 2.0 and $2.5 \AA$, respectively (Figure 6B). A weaker peak is expected for the correlation across the hydrogen bond, as the involved distance is on the order of $3.1 \AA$. A similar distance is expected for a hydrogen bond in an $\alpha$-helix. Figure $6 \mathrm{~A}$ shows a representative strip of a ${ }^{1} \mathrm{H}$ detected HETCOR spectrum (the pulse scheme is shown in Figure 3 of the Supporting Information). For the amide proton frequency of M25, we observe four cross peaks: The two most prominent peaks are due to the correlations $\mathrm{H}^{\mathrm{N}}-\mathrm{CO}_{i-1}$ and $\mathrm{H}^{\mathrm{N}}-\mathrm{CO}_{i}$ within the polypeptide chain. Cross-validation is easily accomplished by comparing the ${ }^{1} \mathrm{H},{ }^{13} \mathrm{C} \mathrm{CP}$ spectrum with the respective strips taken from an $\mathrm{HNCO}$ and an $\mathrm{HNCACO}$ experiment. ${ }^{30}$ The correlation at a carbonyl chemical shift of $174.1 \mathrm{ppm}$ corresponds to the correlation across the hydrogen bond to Y15-CO. A fourth, weak peak can be assigned to the correlation $\mathrm{H}^{\mathrm{N}}-\mathrm{CO}_{i-2}$, i.e., to the cross peak between $\mathrm{M} 25-\mathrm{H}^{\mathrm{N}}$ and T23-CO (corresponding to a distance of $4.0 \AA$ ). In practice, $\mathrm{HNCO}$ and HNCOCA spectra are not required to identify the correlation across the hydrogen bond, as the intensities of the peaks are indicative for their assignments: Decreasing cross peak intensities are expected for correlations $\mathrm{H}^{\mathrm{N}}-\mathrm{CO}_{i-1}>\mathrm{H}^{\mathrm{N}}-\mathrm{CO}_{i}$ $>\mathrm{H}^{\mathrm{N}}-\mathrm{CO}_{\text {cross-strand }}$.

In the experiment, a CP contact time of $10 \mathrm{~ms}$ was employed to probe long-range transfers. In practice, such long contact times are not required. The ideal mixing time is on the order of $1.5-1.7 \mathrm{~ms}$ (to transfer via a $1.1 \mathrm{kHz}{ }^{1} \mathrm{H},{ }^{13} \mathrm{C}$ dipolar coupling, corresponding to a $3.0 \AA$ distance). The spectrum presented here was recorded as a two-dimensional experiment. Obviously, the

(70) Reif, B.; van Rossum, B. J.; Castellani, F.; Rehbein, K.; Diehl, A.; Oschkinat, H. J. Am. Chem. Soc. 2003, 125, 1488-1489. 
A)

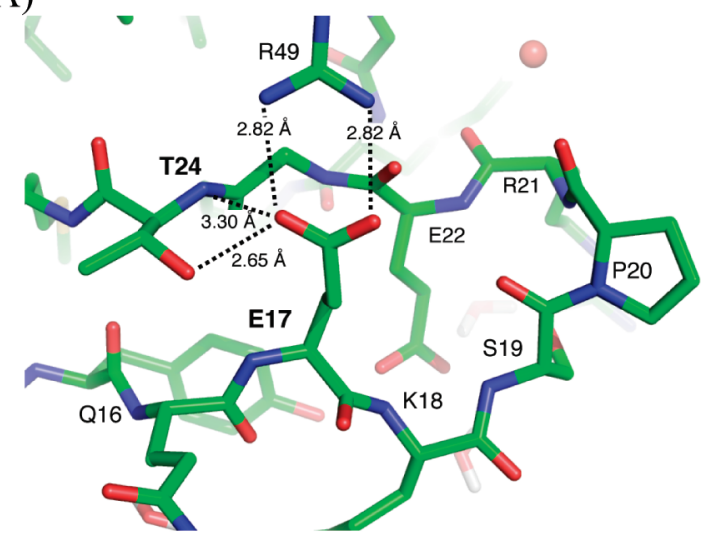

C)

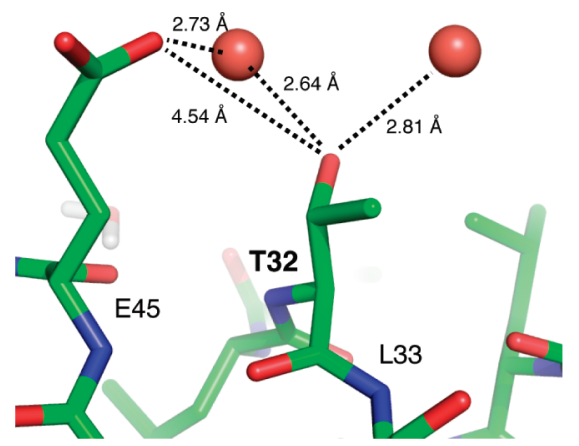

B)

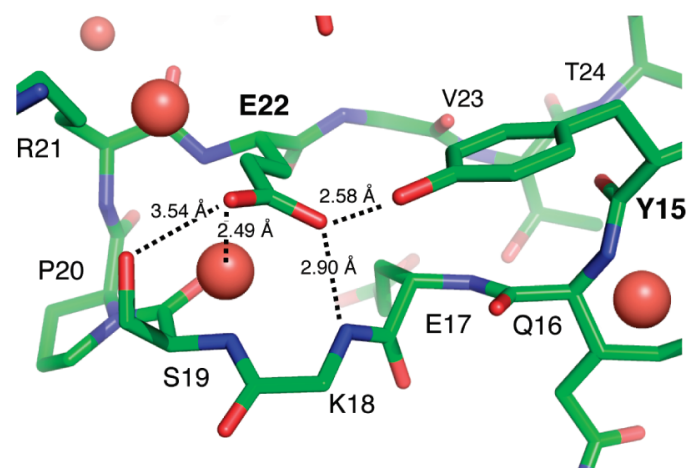

D)

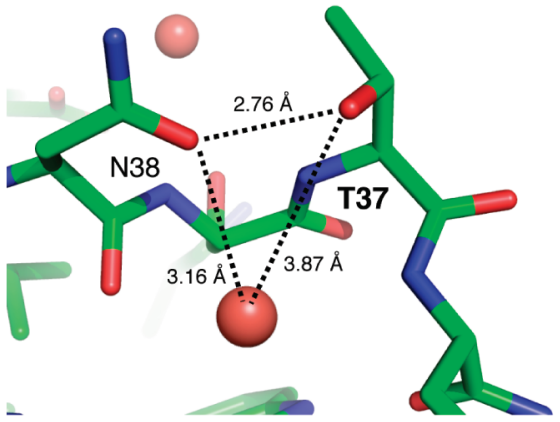

Figure 7. Schematic representation of the RT loop in the $\alpha$-spectrin SH3 domain (PDB code $2 \mathrm{NUZ}$ ). ${ }^{53}$ The X-ray structure was determined at room temperature. The loop is stabilized by side chain hydrogen bonds involving T24-E17 (A) and Y15-E22 (B). Tentative hydrogen bonds are indicated with dashed lines. (C and D) The structure around residues T32 and T37, respectively. Water molecules are represented as red spheres.

resolution is insufficient, and a ${ }^{15} \mathrm{~N}$ dimension would be required to assign all correlations, as the number of cross peaks is increased by a factor of 2-3 compared to a HNCO spectrum. Work in this directon is currently in progress in our laboratory.

\section{Discussion}

In the following, the above presented findings will be discussed by employing the room temperature crystal structure of the $\alpha$-spectrin SH3 domain. Figure 7 focuses on the extended RT loop of the protein. Tentative hydrogen bonds are indicated as dashed lines. The hydroxyl oxygen of T24 is in close vicinity $(2.65 \AA)$ to one of the oxygen atoms of the carboxylic group of E17. The ${ }^{13} \mathrm{C}$-detected ${ }^{1} \mathrm{H},{ }^{13} \mathrm{C} \mathrm{CP}$ correlation spectrum (Figure 4) yields a correlation signal between $\mathrm{T} 24-\mathrm{OH}(8.35 \mathrm{ppm})$ and the carbon resonances of $\mathrm{E} 17-\mathrm{COO}^{-}$and $\mathrm{T} 24-\mathrm{C} \beta$. In addition, the carboxylic group of E17 seems to be involved in a salt bridge to the side chain of R49. In fact, $\mathrm{T} 24-\mathrm{OH}$ shows a weak correlation to arginine $\mathrm{C} \zeta$.

The structure around T32 and T37 is depicted in Figure 7C,D. The hydroxyl group of T32 is surrounded by two crystallographic water molecules (ca. $2.7 \AA$ A). Figure 2 shows that T32$\mathrm{OH}$ is very susceptible to changes in temperature and moves upfield upon increase of the temperature. At the same time, a cross peak at the water frequency is observed (at $25{ }^{\circ} \mathrm{C}$ ), indicating chemical exchange with water. The hydroxyl oxygen of T37 is in close proximity to the side chain carbonyl oxygen of N38 (2.7 $\AA$ ) and is presumably involved in a hydrogen bond. Similar to T24-OH, the resonance frequency of T37-OH shows only very little variations over a temperature range of $30{ }^{\circ} \mathrm{C}$. T37-OH-in contrast to T24 and T32-does not exchange with water even at $25{ }^{\circ} \mathrm{C}$ (Figure 2). This behavior is in agreement with the observed hydroxyl proton line widths. At $5{ }^{\circ} \mathrm{C}$, the observed line width for the three hydroxyl protons $\mathrm{T} 24-\mathrm{OH}$, $\mathrm{T} 32-\mathrm{OH}$, and $\mathrm{T} 37-\mathrm{OH}$ are 113,100 , and $50 \mathrm{~Hz}$, respectively. The T37-OH line width is limited only by the acquisition time in the indirect dimension. The stability of this hydroxyl proton might be due to the absence of acidic or basic side chains in the vicinity of this residue, which could catalyze the exchange process.

Even though the exchange characteristics of serines should be comparable to those of threonine, ${ }^{10}$ we cannot find resolved serine hydroxyl resonances in the $\alpha$-spectrin SH3 domain. We speculate that the serine hydroxyl chemical shifts accidentally coincide with the water chemical shift. Neither S19 nor S36 are involved in a side chain hydrogen bond. The appearance of a shoulder for S36-OH downfield of the water resonance supports this interpretation. The $\mathrm{S} 19-\mathrm{OH}$ resonance disappears at $-4{ }^{\circ} \mathrm{C}$ (data not shown). This is possibly due to exchange broadening as rotations of the side chain around $\chi_{1}$ might be hindered at low temperature.

Carbon resonances of Y57 display only correlations to protons involving the water frequency at all temperatures investigated. This is in agreement with the fact that this residue is solvent exposed. The respective hydroxyl group can exchange rapidly with the solvent. Y15-C $\xi$ shows only at a temperature of $25^{\circ} \mathrm{C}$ a correlation to water, indicating that the hydroxyl proton is partially protected from exchange. In fact, the hydroxyl group of Y15, the side chain carboxylic group of E22, and a water molecule are forming an extended network of hydrogen bonds (Figure 7). Y15-OH is within hydrogen bonding distance to one 
of the carboxylic oxygens of the side chain of E22. This hydrogen bond is stabilized by the aliphatic side chain of K18, which is oriented in parallel to the hydrogen bond. The second oxygen of the carboxylic group is in the vicinity of two water molecules. Interestingly, we observe two correlations for E22$\mathrm{C} \delta$ involving a correlation to $\mathrm{Y} 15-\mathrm{H} \eta$ and water (Figure 3). A comparable exchange peak is missing for E17-C $\delta$. Two explanations can account for this observation: First, the correlation peak at the water frequency for E22-C $\delta$ is due to a direct dipolar transfer between a water molecule and the carboxylic carbon of E22. The ${ }^{1} \mathrm{H},{ }^{13} \mathrm{C}$ distance for this transfer would be on the order of $2.5 \AA$. Second, E22 has a relatively high $\mathrm{p} K_{\mathrm{a}}\left(\mathrm{p} K_{\mathrm{a}}>7\right)$. The fact that we do not observe a distinct hydroxyl chemical shift for E22 suggests that the solvent exchange rate is high. The environment around the carboxylic group of E22 is in fact very hydrophobic and only solvent accessible from one side with a water molecules within a distance of $2.5 \AA$. The carboxylic group of E22 is flanked by the side chains of $\mathrm{Y} 15$ and $\mathrm{K} 18$ and the indole ring of W41 (3.6 ̊). The second explanation seems more likely, as the residence time of a water molecule on the surface of a protein is on the order of nanoseconds, ${ }^{72,73}$ which would truncate the dipolar transfer between water and the protein. E22 is in fact not involved in any crystal contacts to a symmetry-related molecule which, in turn, would justify a longer residence time. This interpretation is in agreement with the observation that correlations between water and the protein are in general only

(71) Wasmer, C.; Lange, A.; Van Melckebeke, H.; Siemer, A. B.; Riek, R.; Meier, B. H. Science 2008, 319, 1523-1526.

(72) Halle, B. Water in biological systems: The NMR picture In Hydration Processes in Biology; Bellisent-Funel, M.-C., Ed.; IOS Press: Dordrecht, 1998; pp 233-249.

(73) Gottschalk, M.; Dencher, N. A.; Halle, B. J. Mol. Biol. 2001, 311, 605-621. observed as a consequence of chemical exchange, as we have pointed out above.

\section{Conclusion}

In conclusion, we have shown that hydroxyl protons in a perdeuterated microcrystalline protein can be observed by MAS solid-state NMR spectroscopy. Dipolar couplings allow one to transfer magnetization 50 times faster compared to sequences that rely on scalar couplings and thus enable assignment of hydroxyl protons that are even in fast exchange with the solvent. $T_{1}$ decay rates for hydroxyl groups that are involved in a hydrogen bond show a biexponential behavior, which is consistent with a model in which the hydroxyl proton can be in an open or a closed state. Quantification of dipolar couplings allow furthermore one to localize the position of the hydroxyl proton in a hydrogen bond. We believe that, in addition to interpretation of proton isotropic chemical shifts, knowledge about the position of the hydroxyl proton will allow a better quantification of the strength of a hydrogen bond. Similar longrange ${ }^{1} \mathrm{H},{ }^{13} \mathrm{C}$ dipolar correlation experiments are carried out to identify backbone hydrogen bonds in the $\alpha$-spectrin SH3 domain. We anticipate that these experiments will be useful in the future for the characterization of the registry of $\beta$-strand arrangement in amyloid fibrils.

Acknowledgment. We thank Dr. P. Tolstoy and Prof. Dr. H. H. Limbach for stimulating discussions. This work was supported by the Leibniz-Gemeinschaft and the DFG (Grants Re1435, SFB 449, SFB 740).

Supporting Information Available: RF pulse schemes and detailed experimental information for the ${ }^{13} \mathrm{C}$ and ${ }^{1} \mathrm{H}$ detected ${ }^{1} \mathrm{H},{ }^{13} \mathrm{C} \mathrm{CP}$, exchange, and REDOR experiments and the hydroxyl-methyl region of the ${ }^{13} \mathrm{C}$-detected HETCOR spectrum. This material is available free of charge via the Internet at http://pubs.acs.org.

JA910167Q 